\title{
AUDIT KESELAMATAN JALAN TOL JAGORAWI
}

\author{
Ni Luh Shinta Putu Eka Setyarini ${ }^{1}$, Bryan Ivan Lukitoº \\ ${ }^{1}$ Program Studi Sarjana Teknik Sipil, Universitas Tarumanagara \\ Email: shintarachmat@yahoo.com \\ ${ }^{2}$ Program Studi Sarjana Teknik Sipil, Universitas Tarumanagara \\ Email: bryanivanlukito@gmail.com
}

\begin{abstract}
ABSTRAK
Ruas jalan tol Jagorawi merupakan jalan bebas hambatan yang dibutuhkan untuk mempercepat waktu tempuh dari Jakarta ke Bogor dan Ciawi, kondisi jalan tol Jagorawi saat ini sangat padat yang berakibat kepada meningkatnya jumlah kecelakaan lalu lintas. Dalam upaya meningkatkan keselamatan lalu lintas jalan di jalan tol, maka perlu melaksanakan Audit Keselamatan Jalan (AKJ). Aspek jalan yang menjadi objek untuk diperiksa meliputi aspek geometrik jalan, manajemen lalu lintas, bangunan pelengkap jalan dan pelengkap jalan. Hasilnya, dari segi geometrik, secara umum jalan sudah dirancang sesuai dengan ketentuan yang berlaku, namun, terdapat bagian-bagian dari jalan tol yang masih memerlukan perbaikan. Penelitian ini akan membahas mengenai kondisi eksisting jalan Tol Jagorawi berdasarkan pengamatan langsung yang dilaksanakan di lapangan dengan mempergunakan formulir audit keselamatan jalan untuk jalan yang sudah operasional. Aspek yang ditinjau adalah aspek geometrik, perkerasan, bangunan pelengkap jalan dan pelengkap jalan. Sebagai hasil akhir, didapat daerah rawan kecelakaan pada ruas Tol Jagorawi dengan analisis dari hasil pengamatan langsung, dan dari data kecelakaan lalu lintas yang diperoleh dari Jasa Marga.
\end{abstract}

Kata Kunci: audit keselamatan; daerah rawan kecelakaan; jalan tol

\section{ABSTRACT}

Jagorawi toll road is a link road needed to speed up travel time from Jakarta to Bogor and Ciawi, the condition of Jagorawi is currently very congested resulting in an increasing number of traffic accidents. To improve road traffic safety on toll roads, it's necessary to carry out Road Safety Audits (RSA). Aspects of the road that become objects to examine and direct observations included geometric aspects, traffic management, pavement, road complementary buildings and street furnitures. As a result, in geometric aspect, in general the road has been designed in accordance regulations, however, there are parts of the toll road that still require repair. This research will discuss regard the condition of Jagorawi toll road based on direct observations carried out in the field by using road safety audit form for operational roads. The aim is, accident-prone areas are obtained on Jagorawi toll road with analysis of the results of direct observations, and from traffic accident data obtained from Jasa Marga

Keywords: accident prone areas; road safety audit; toll road

\section{PENDAHULUAN}

Jalan tol berperan penting dalam meningkatkan aksesibilitas dan pertumbuhan ekonomi di Indonesia hal ini mengacu kepada Peraturan Pemerintah Republik Indonesia Nomor 15 Tahun 2005 tentang Jalan Tol, penyelenggaraan jalan tol dimaksudkan untuk mewujudkan pemerataan pembangunan serta keseimbangan dalam pengembangan wilayah dengan memperhatikan keadilan, terutama untuk wilayah yang tingkat perkembangannya sudah cukup tinggi. Hal ini ditandai dengan gencarnya usaha Pemerintah untuk membangun infrastruktur jalan tol pada 5 tahun terakhir ini, tetapi tidak bisa dilupakan jalan tol pertama yang dibangun di Indonesia adalah Tol Jagorawi. Jalan ini diresmikan pada tahun 1978 dan memiliki kualitas infrastruktur yang sangat baik dan terpelihara sampai saat ini. 
Infrastruktur jaringan jalan tol di Indonesia sempat mengalami pertumbuhan yang lambat selama beberapa tahun (sebelum tahun 2015) dan menunjukkan pemeliharaan jaringan jalan yang kurang memadai. Kondisi ini menghasilkan lalu lintas yang sangat padat dan jumlah kecelakaan lalu lintas yang tinggi. Menurut Tollazzia dan Rencelj (2012), Mohammed (2013), Amirthalingam dan Vayalamkuzhi (2016), serta Naveen dkk. (2018), beberapa parameter geometrik jalan yang mempengaruhi terjadinya kecelakaan adalah kecepatan setempat, lebar dan jumlah lajur, lebar dan jenis bahu, lebar dan jenis median, adanya lajur mendaki, radius tikungan yang tajam, superelevasi, lengkung, jarak pandang, kelandaian, marka jalan, dan kondisi permukaan jalan. Menurut Soehodho (2017), kecelakaan lalu lintas disebabkan oleh tiga jenis faktor yang berbeda, yaitu, faktor manusia, faktor kendaraan, dan faktor eksternal (termasuk kondisi jalan).

Menurut Wegman (2017), kecelakaan yang serius akan tetap terjadi apabila kita meninggalkan persoalan kondisi jalan yang tidak aman terhadap pengguna. Menurut WHO (2018), Peningkatan kecelakaan lalu lintas tidak boleh disepelekan, karena pada dasarnya kecelakaan lalu lintas adalah predictable dan preventable. Berdasarkan data WHO (2018), jumlah korban meninggal akibat kecelakaan lalu lintas terus meningkat, mencapai 1.35 juta kematian sepanjang tahun 2016 . Kecelakaan lalu lintas merupakan penyebab utama kematian bagi anak dan dewasa muda berusia $5-29$ tahun. Selain itu, kecelakaan lalu lintas menempati peringkat ke 8 sebagai penyebab utama kematian bagi orang dari segala usia.

Oleh karena itu, diperlukan Audit Keselamatan Jalan (AKJ) untuk mengurangi jumlah korban kecelakaan. Menurut Nishimura (2017), AKJ merupakan pemeriksaan keselamatan jalan formal jalan atau proyek lalu lintas, atau jenis lain dari proyek keselamatan yang mempengaruhi pengguna jalan, yang dilakukan oleh auditor independen atau tim auditor, memiliki kualifikasi yang melaporkan potensi kecelakaan proyek dan kinerja keselamatan untuk semua jenis pengguna jalan. Audit keselamatan jalan merupakan bagian dari strategi pencegahan dari kecelakaan lalu lintas. (Weller, et al., 2006, Ram 2013, Gitelman dan Doveh, 2016, dan Persia, 2016). Untuk melaksanakan audit/pemeriksaan keselamatan jalan secara komprehensif, sistematis dan independen dilakukan oleh seorang auditor yang memiliki pengetahuan tentang peraturan, perencanaan dan pelaksanaan pekerjaan konstruksi, desain geometrik dan bangunan pelengkap, serta pelengkap jalan yang berpotensi mengakibatkan konflik lalu lintas (Vardaki et al, 2018). Menurut Mulyono, dkk. (2009), fakta di lapangan menunjukkan banyak tikungan jalan yang tidak dilengkapi dengan rambu batasan kecepatan yang disesuaikan dengan fungsi jalan dan banyak ruas-ruas jalan baik bagian lurus maupun tikungan yang dibangun secara substandar karena kesulitan kelayakan fisiografi trase jalan. Selain itu, banyak ruas jalan yang rusak tidak dilengkapi rambu-rambu peringatan dan petunjuk lokasi kerusakan struktural jalan.

Tujuan penelitian ini adalah untuk membandingkan kondisi eksisting geometrik, perkerasan, bangunan pelengkap dan perlengkapan jalan Tol Jagorawi terhadap standar teknis keselamatan jalan sehingga diperoleh daerah rawan kecelakaan melalui pengamatan langsung. Kemudian daerah rawan kecelakaan dari hasil pengamatan langsung dibandingkan dengan daerah rawan kecelakaan dari data sekunder, yaitu data kecelakaan lalu lintas yang diperoleh dari Jasa Marga. Penelitian ini diharapkan dapat memberikan identifikasi dan analisis faktor - faktor yang yang menjadi menyebabkan kecelakaan di Tol Jagorawi. Selain itu, penelitian ini diharapkan dapat menemukan solusi yang dapat dijadikan pertimbangan untuk instansi terkait dalam hal keselamatan di jalan Tol Jagorawi. 


\section{METODE PENELITIAN}

\section{Tahapan penelitian}

Tahapan penelitian dibuat untuk menjadi panduan dalam pelaksanaan penelitian agar penelitian terlaksana sesuai dengan tahapan yang di desain. Tahapan penelitian pada penyusunan penelitian ini dapat dilihat pada Gambar 1.

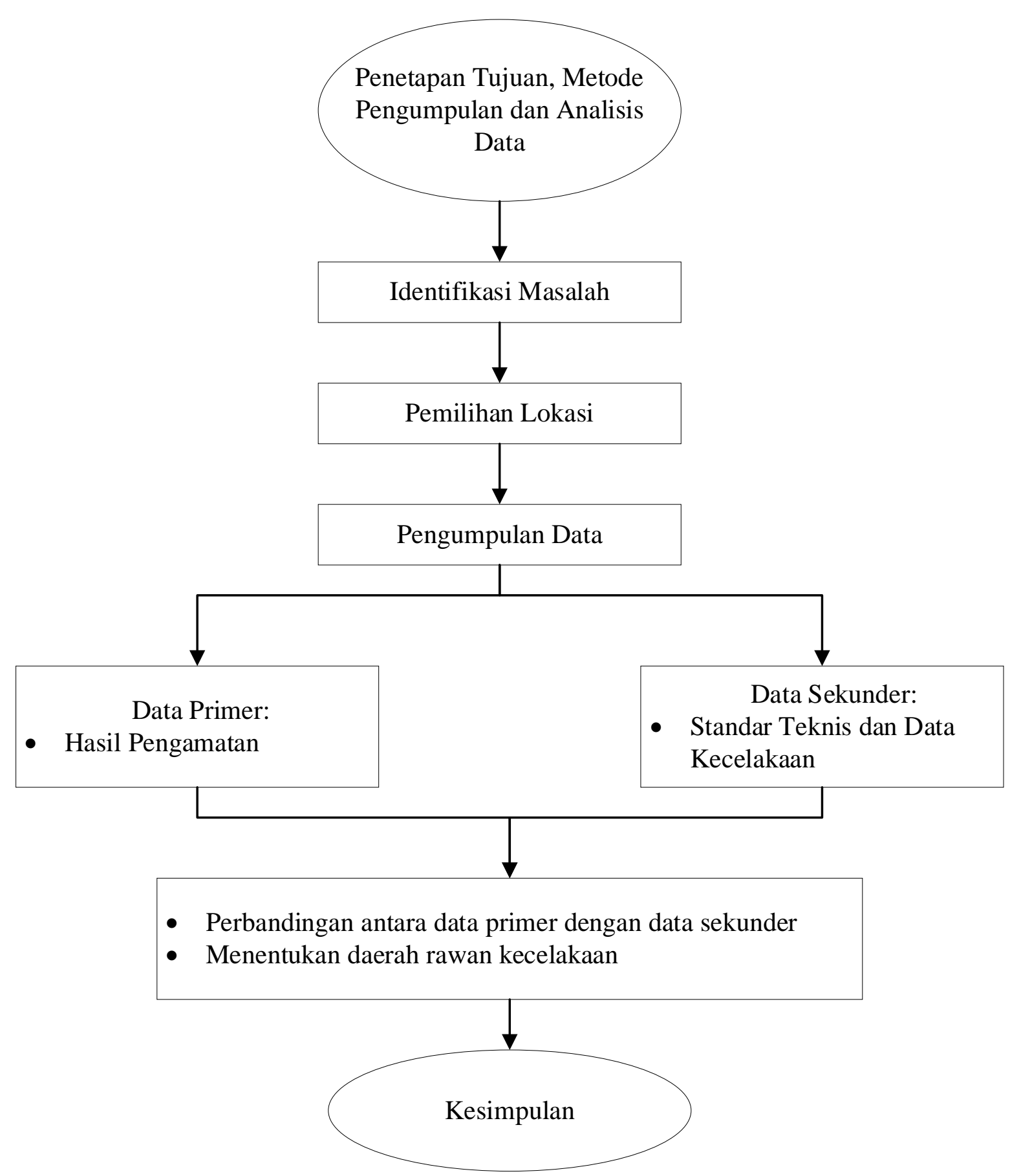

Gambar 1. Tahapan Penelitian 


\section{Metode Penelitian}

Metode yang digunakan dalam penelitian ini adalah:

a. Studi literatur atau kepustakaan, dengan berbagai sumber, seperti buku, peraturan yang terkait, jurnal ilmiah, dan tulisan - tulisan yang berkaitan dengan masalah yang dibahas.

b. Metode observasi langsung di lapangan dengan melihat dan meneliti langsung kondisi jalan sesuai lokasi yang ditentukan dengan memperhatikan aspek geometrik, perkerasan, bangunan pelengkap, dan perlengkap jalan.

c. Metode Equivalent Accident Number / Angka Ekivalen Kecelakaan (EAN/AEK) untuk mendapatkan daerah rawan kecelakaan dari data kecelakaan lalu lintas, diperoleh dari data sekunder kecelakaan Jasa Marga dengan mempergunakan faktor koefisien dari Jasa Marga. Nilai bobot standar yang digunakan adalah Meninggal Dunia $(\mathrm{MD})=12$, Luka Berat $(\mathrm{LB})=6$, Luka Ringan $(L R)=3$, Kerusakan kendaraan $(K)=1$.

d. Daerah rawan kecelakaan akan teridentifikasi bila hasil perhitungan EAN/AEK > BKA (Batas Kontrol Atas) dan UCL (Upper Control Limit), yang perlu mendapatkan penanganan untuk mengurangi jumlah dan fatalitas kecelakaan.

\section{Metode Pengumpulan Data}

Data yang dikumpulkan dibagi menjadi data primer dan data sekunder,data primer yang dimaksud adalah data observasi lapangan yang dilakukan di lokasi yaitu ruas jalan Tol Jagorawi. Untuk observasi lapangan, data akan diambil dengan direkam menggunakan kamera GoPro dan hasil video diteliti kembali dengan memperhatikan aspek geometrik, perkerasan, bangunan pelengkap jalan dan perlengkapan jalan. Data sekunder yang dimaksud adalah standar teknis dari Departemen Pekerjaan Umum dan Departemen Perhubungan sebagai perbandingan terhadap kondisi eksisting jalan Tol Jagorawi. Data kecelakaan lalu lintas di jalan Tol Jagorawi diperoleh dari PT Jasa Marga. Standar teknis dari Departemen Pekerjaan Umum dan Departemen Perhubungan diperoleh dari website Departemen Pekerjaan Umum dan Departemen Perhubungan.

\section{HASIL DAN PEMBAHASAN}

\section{Penentuan titik rawan kecelakaan dengan metode EAN/AEK}

Metode untuk menghitung angka kecelakaan adalah dengan menggunakan metode EAN (Equivalent Accident Number) oleh Pignataro (dalam Juhendra, 2015). Metode EAN merupakan pembobotan angka ekivalen kecelakaan yang mengacu pada biaya kecelakaan lalu lintas. EAN dihitung dengan menjumlahkan kejadian kecelakaan pada setiap kilometer panjang jalan kemudian dikalikan dengan nilai bobot sesuai tingkat keparahan. Menurut Sulistyono (dalam Sugiyanto dan Fadli, 2017), nilai bobot standar yang digunakan adalah Meninggal Dunia (MD) $=12$, Luka Berat $(\mathrm{LB})=6$, Luka Ringan $(\mathrm{LR})=3$, Kerusakan kendaraan $(K)=1$, yang dinyatakan dalam rumus:

$\mathrm{EAN} / \mathrm{AEK}=12 \mathrm{MD}+6 \mathrm{LB}+3 \mathrm{LR}+1 \mathrm{~K}$

Penentuan lokasi rawan kecelakaan dilakukan berdasarkan angka kecelakaan tiap kilometer jalan yang memiliki nilai bobot (EAN) melebihi nilai batas tertentu. Nilai batas ini dapat dihitung antara lain dengan menggunakan metode Batas Kontrol Atas (BKA) dan Upper Control Limit (UCL). Nilai Batas Kontrol Atas (BKA) ditentukan dengan menggunakan persamaan berikut:

$\mathrm{BKA}=\mathrm{C}+3 \sqrt{C}$

dengan $\mathrm{C}=$ Rata - rata angka kecelakaan EAN 
Nilai UCL (Upper Control Limit) ditentukan dengan menggunakan persamaan berikut:

$\mathrm{UCL}=\lambda+\psi+\sqrt{(\lambda / \mathrm{m})+(0.829 / \mathrm{m})+[1 /(2 / \mathrm{m})]}$

dengan: $\lambda=$ Rata-rata angka kecelakaan EAN;

$\Psi=$ Faktor probabilitas $=2.576 \mathrm{~m}=$ Angka kecelakaan ruas yang ditinjau $(\mathrm{AEK})$

Metode Upper Control Limit (UCL) dan metode Batas Kontrol Atas (BKA) digunakan untuk menentukan lokasi titik rawan kecelakaan lalu lintas. Menurut Sugiyanto dan Fadli (2017), suatu ruas jalan atau segmen akan diidentifikasi sebagai lokasi titik rawan kecelakaan lalu lintas jika jumlah angka ekivalen kecelakan lebih besar dibandingkan dengan nilai UCL atau nilai BKA.

\section{Hasil analisis pengamatan langsung pada tahun 2019}

Hasil pengumpulan data karakteristik jalan dibuat dalam bentuk strip map untuk mempermudah melihat rambu, marka, dan median pada setiap lokasi. Berdasarkan Peraturan Menteri Perhubungan Nomor 13 Tahun 2014 Tentang Rambu Lalu Lintas pasal 39 ayat 2, penempatan rambu peringatan sebelum tempat berbahaya harus terpasang paling sedikit setiap 80 meter pengulangan untuk jalan dengan kecepatan rencana 60 km/jam hingga $80 \mathrm{~km} / \mathrm{jam}$ dan 100 meter pengulangan untuk jalan dengan kecepatan rencana $80 \mathrm{~km} / \mathrm{jam}$ hingga $100 \mathrm{~km} / \mathrm{jam}$. Hasil pengamatan menunjukkan terdapat kekurangan rambu perintah dan peringatan di sepanjang jalan Tol Jagorawi. Hasil analisis pengamatan langsung dapat dilihat pada Tabel 1.

Tabel 1. Hasil Analisis Pengamatan Langsung pada tahun 2019

\begin{tabular}{cccc}
\hline KM & $\begin{array}{c}\text { Kondisi Geometrik } \\
\text { Jalan }\end{array}$ & Kondisi Perkerasan Jalan & Rambu Jalan \\
\hline $9.70-9.80$ & Tikungan ke kiri & Jalan tidak rata & $\begin{array}{c}\text { Dilarang menggunakan bahu jalan } \\
\text { kecuali darurat }\end{array}$ \\
\hline $28.50-28.60$ & Lurus dan menurun & Jalan sudah rata dan halus & Dilarang memutar kecuali petugas \\
\hline $44.80-44.90$ & Lurus dan menurun & Jalan tidak rata & Dilarang berhenti \\
\hline $5.90-5.80$ & Tikungan ke kiri & Jalan sudah rata dan halus & Dilarang berhenti \\
\hline $31.80-31.70$ & Lurus & Jalan sudah rata dan halus & $\begin{array}{c}\text { Dilarang membuang benda apapun } \\
\text { ke jalan tol }\end{array}$ \\
\hline $43.20-43.10$ & Lurus dan menurun & Jalan sudah rata dan halus & $\begin{array}{c}\text { Perintah pedoman jarak 200 m di } \\
\text { depan }\end{array}$ \\
\hline
\end{tabular}

Berdasarkan hasil pengamatan langsung, terdapat beberapa titik jalan dengan kekurangan rambu. Kekurangan rambu pada beberapa titik jalan merupakan bentuk pelanggaran terhadap Peraturan Menteri Perhubungan Nomor 13 Tahun 2014. Dari Tabel 1 dapat dilihat titik jalan dengan perkerasan jalan tidak rata, seperti pada KM44+80 - KM44+90. Ketidakrataan jalan membuat ketidaknyamanan bagi pengguna 


\section{Hasil analisis data kecelakaan dengan metode EAN}

Data kecelakaan di jalan Tol Jagorawi diperoleh dari PT Jasa Marga. Data kecelakaan di jalan Tol Jagorawi pada tahun 2018 dapat dilihat pada Tabel 2. Sedangkan, perhitungan dengan metode EAN dapat dilihat pada Tabel 3.

Tabel 2. Data Kecelakaan di Jalan Tol Jagorawi Tahun 2018

\begin{tabular}{cccccc}
\hline Ruas Jalan & KM & $\begin{array}{c}\text { Jumlah } \\
\text { Kecelakaan }\end{array}$ & $\begin{array}{c}\text { Meninggal } \\
\text { Dunia }\end{array}$ & Luka Berat & $\begin{array}{c}\text { Luka } \\
\text { Ringan }\end{array}$ \\
\hline Cililitan - TMII & $0-5.2$ & 5 & 0 & 1 & 4 \\
\hline TMII - Pasar Rebo & $5.2-7.3$ & 7 & 1 & 5 & 7 \\
\hline Pasar Rebo - Cibubur & $7.3-14.1$ & 17 & 2 & 8 & 11 \\
\hline Cibubur - Cimanggis & $14.1-19.6$ & 27 & 3 & 6 & 10 \\
\hline Cimanggis - Gunung Putri & $19.6-24.1$ & 18 & 2 & 3 & 8 \\
\hline Gunung Putri - Citereup & $24.1-27.4$ & 12 & 0 & 3 & 10 \\
\hline Citereup - Sentul & $27.4-33.2$ & 13 & 0 & 7 & 7 \\
\hline Sentul - Sentul Selatan & $33.2-36.8$ & 9 & 2 & 9 & 23 \\
\hline Sentul Selatan - Bogor & $36.8-40.2$ & 17 & 5 & 4 & 18 \\
\hline Bogor - Ciawi & $40.2-46.5$ & 16 & 3 & & 7 \\
\hline
\end{tabular}

Data kecelakaan ruas jalan Tol Jagorawi yang diperoleh dari data sekunder Jasa Marga, yang akan di pergunakan untuk menghitung fatalitas kecelakaan dengan metode EAN

Tabel 3. Hasil perhitungan metode EAN

\begin{tabular}{cccccccc}
\hline \multirow{2}{*}{ Ruas Jalan } & \multirow{2}{*}{ KM } & \multicolumn{2}{c}{ Angka Ekivalen Kecelakaan (AEK) } & UCL & BKA \\
\cline { 3 - 8 } & & $12 *$ MD & $6 *$ LB & $3 *$ LR & Total & & \\
\hline Cililitan - TMII & $0-5.2$ & 0 & 6 & 12 & 18 & 97.8199 & 116.3745 \\
\hline TMII - Pasar Rebo & $5.2-7.3$ & 12 & 30 & 21 & 63 & 102.9785 & 116.3745 \\
\hline Pasar Rebo - Cibubur & $\mathbf{7 . 3 - 1 4 . 1}$ & $\mathbf{2 4}$ & $\mathbf{4 8}$ & $\mathbf{4 5}$ & $\mathbf{1 1 7}$ & $\mathbf{1 0 8 . 0 3 0 3}$ & $\mathbf{1 1 6 . 3 7 4 5}$ \\
\hline Cibubur - Cimanggis & $\mathbf{1 4 . 1}-\mathbf{1 9 . 6}$ & $\mathbf{3 6}$ & $\mathbf{4 8}$ & $\mathbf{5 4}$ & $\mathbf{1 3 8}$ & $\mathbf{1 0 9 . 6 9 7 7}$ & $\mathbf{1 1 6 . 3 7 4 5}$ \\
\hline Cimanggis - Gunung Putri & $19.6-24.1$ & 24 & 30 & 30 & 84 & 105.1037 & 116.3745 \\
\hline Gunung Putri - Citereup & $24.1-27.4$ & 0 & 18 & 24 & 42 & 100.5862 & 116.3745 \\
\hline Citereup - Sentul & $27.4-33.2$ & 0 & 18 & 30 & 48 & 101.2983 & 116.3745 \\
\hline Sentul - Sentul Selatan & $33.2-36.8$ & 24 & 42 & 21 & 87 & 105.3886 & 116.3745 \\
\hline Sentul Selatan - Bogor & $\mathbf{3 6 . 8}-\mathbf{4 0 . 2}$ & $\mathbf{6 0}$ & $\mathbf{5 4}$ & $\mathbf{6 9}$ & $\mathbf{1 8 3}$ & $\mathbf{1 1 2 . 9 0 6 3}$ & $\mathbf{1 1 6 . 3 7 4 5}$ \\
\hline Bogor - Ciawi & $40.2-46.5$ & 36 & 24 & 42 & 102 & 106.7531 & 116.3745 \\
\hline
\end{tabular}

Dari tabel 3 hasil dari perhitungan dengan metode EAN, terdapat 3 area rawan kecelakaan di ruas Tol Jagorawi yaitu ruas jalan Pasar Rebo - Cibubur, Cibubur - Cimanggis dan Sentul Selatan Bogor. Contoh perhitungan AEK di ruas Sentul Selatan - Bogor dengan jumlah korban meninggal dunia 5 orang, jumlah korban luka berat 9 orang, dan jumlah korban luka ringan 23 orang. Nilai angka ekivalen dihitung dengan persamaan 1 dan diperoleh nilai AEK sebesar 183. Jumlah angka ekivalen kecelakaan (m) di ruas Sentul Selatan - Bogor adalah 183. Setelah semua nilai AEK 
dihitung, langkah selanjutnya adalah mencari nilai rata-rata kecelakaan $(\lambda)$ yang diperoleh dari jumlah nilai AEK dibagi dengan jumlah ruas jalan. Nilai rata-rata kecelakaan $(\lambda)$ pada tahun 2018 didapat sebesar $882 / 10=88.2$. Perhitungan nilai batas dilakukan untuk mengetahui batas tingkat kerawanan kecelakaan tiap ruas jalan, di mana setiap ruas jalan memiliki batas tingkat kerawanan kecelakaan yang berbeda-beda. Perhitungan ini menjadi acuan untuk menentukan ruas jalan yang termasuk daerah rawan kecelakaan di jalan Tol Jagorawi.

Nilai Batas Kontrol Atas diperoleh dengan memasukkan nilai rata-rata angka ekivalen kecelakaan sebesar 88.2 ke persamaan 2 dan diperoleh nilai BKA sebesar 116.3745. Contoh perhitungan nilai UCL (Upper Control Limit) pada ruas jalan Sentul Selatan - Bogor dengan data angka kecelakaan rata-rata $(\lambda)=88.2$; nilai faktor probabilitas $(\Psi)=2,576$, dan jumlah angka ekivalen kecelakaan $(\mathrm{m})=183$. Dari persamaan 3, diperoleh nilai Upper Control Limit pada ruas jalan Sentul Selatan - Bogor sebesar 112.9063.

Berdasarkan hasil analisis data kecelakaan lalu lintas, nilai angka ekivalen kecelakaan, nilai Upper Control Limit di setiap ruas jalan, dan nilai Batas Kontrol Atas, lokasi rawan kecelakaan lalu lintas dapat diidentifikasi di jalan Tol Jagorawi. Identifikasi dilakukan dengan memperhatikan jumlah AEK > nilai Upper Control Limit dan AEK > nilai Batas Kontrol Atas. Hasil identifikasi lokasi rawan kecelakaan lalu lintas menunjukkan terdapat tiga ruas jalan dengan persyaratan tersebut, yaitu ruas Pasar Rebo - Cibubur, Cibubur - Cimanggis, dan Sentul Selatan - Bogor.

\section{KESIMPULAN DAN SARAN}

\section{Kesimpulan}

Berdasarkan analisis data penelitian yang telah dilakukan, kesimpulan yang didapat berdasarkan hasil pengamatan langsung:

a. Kondisi perkerasan jalan eksisting pada jalan Tol Jagorawi sudah cukup baik, namun pada beberapa titik ruas jalan kondisi perkerasannya tidak rata dan berlubang. Titik jalan dengan kondisi perkerasan tidak rata dan berlubang pada jalan lurus antara lain pada KM18+90, $\mathrm{KM} 30+20$, dan KM33+20 arah Ciawi serta KM28+70, KM45+10, dan KM45+60 arah Jakarta.

b. Terdapat kekurangan rambu pada beberapa ruas jalan Tol Jagorawi. Hal ini tidak sesuai dengan Peraturan Menteri Perhubungan Nomor 13 Tahun 2014, yaitu tidak adanya rambu peringatan untuk memperingati pengemudi bahwa terjadi perubahan alinyemen horizontal atau vertikal pada ruas jalan. Titik jalan yang kekurangan rambu antara lain pada KM8+00, KM9+50, KM19+00, dan KM28+20, KM29+10, dan KM44+90 arah Ciawi dan KM45+40, KM42+70, KM33+60, KM31+70, KM19+80, dan KM6+20 arah Jakarta.

c. Pada KM 41+80 sampai KM 46+50, kondisi median jalan sudah baik. Namun, tinggi median jalan kurang sehingga tidak dapat menghalangi cahaya kendaraan dari arah berlawanan. Pada KM 0 sampai KM 41+80, kondisi median jalan baik dan dapat menghalangi cahaya kendaraan dari arah berlawanan.

d. Berdasarkan hasil analisis data kecelakaan lalu lintas jalan Tol Jagorawi tahun 2018, dapat disimpulkan bahwa terdapat tiga ruas jalan yang menjadi lokasi rawan kecelakaan lalu lintas, yaitu ruas Pasar Rebo - Cibubur (KM7+30 - KM14+10), Cibubur - Cimanggis (KM14+10 KM19+60), dan Sentul Selatan - Bogor (KM36+80 - KM40+20). Jika dibandingkan dengan pengamatan langsung, pada ruas Pasar Rebo - Cimanggis terdapat kekurangan rambu yang menyatakan perubahan alinyemen pada KM8+00, KM9+50, dan KM19+00 arah Ciawi serta 
KM19+80 arah Jakarta. Selain itu, terdapat beberapa titik jalan yang tidak rata dan berlubang. Pada ruas Sentul Selatan - Bogor, terdapat titik jalan yang tidak rata dan berlubang pada KM37+20 arah Ciawi.

\section{Saran}

Setelah penelitian ini selesai dibuat, penulis ingin memberikan saran untuk penelitian lebih lanjut, yaitu:

a. Menggunakan kamera yang lebih baik untuk pengambilan gambar bangunan pelengkap jalan di jalan tol agar bisa meliputi minimal $135^{\circ}$ sudut pandang.

b. Membawa memori kamera lebih pada saat pengambilan gambar agar dapat menyimpan data lebih besar.

\section{REFERENSI}

Amirthalingam, V., \& Vayalamkuzhi, P. (2016). Influence of Geometric Design Characteristics on Safety Under Heterogeneous Traffic Flow. Journal of Traffic and Transportation engineering, 559-570.

Field, A. (2009). Discovering Statistics Using SPSS 3rd Edition. London: SAGE Publications.

Gitelman, V., \& Doveh, E. (2016). Investigating Road Safety Management Systems in the European Countries: Patterns and Particularities. Journal of Transportation and Technologies, 378-404.

(2018). Global Status Report on Road Safety. Geneva: World Health Organization (WHO).

Juhendra, M., Arliansyah, J., \& Rhaptyalyani. (2015). ANALISIS DAERAH RAWAN KECELAKAAN (BLACKSPOT) DI KOTA PALEMBANG. The 18th FSTPT International Symposium. Lampung: Universitas Lampung.

Mohammed, H. (2013). The Influence of Road Geometric Design Elements on Highway Safety. International Journal of Civil Engineering and Technology, 146-162.

Mulyono, A., Berlian, K., \& Gunawan, H. (2009). Audit Keselamatan Infrastruktur Jalan (Studi Kasus Jalan Nasional KM78-KM79 Jalur Pantura Jawa, Kabupaten Batang). Jurnal Teknik Sipil, 163-174.

Naveen, N., Rajesh, M., Srinivas, M., \& Fasioddin, M. (2017). ROAD SAFETY AUDIT OF A RURAL ROAD. International Journal of Civil Engineering and Technology (IJCIET), 752-761.

Nishimura, M. (2017). Application of Road Safety Audits in Japan - Organizational Culture and Absorptive Capacity Perspectives. Journal of Safety Studies, 1-18.

Persia, L., Usami, D. S., Simone, F. D., Beaumelle, V. F., Yannis, G., Laiou, A., . . Salathè, M. (2016). Management of road infrastructure safety. 6th Transport Research Arena (hal. 3436-3445). Warsaw: Elsevier.

Soehodho, S. (2017). Public Transportation Development and Traffic Accident Prevention in Indonesia. International Association of Traffic and Safety Sciences Research, 76-80.

Sugiyanto, G., \& Fadli, A. (2017). Identifikasi Lokasi Rawan Kecelakaan Lalu Lintas (Black Spot) di Kabupaten Purbalingga, Jawa Tengah. Jurnal Teknik Sipil \& Perencanaan Universitas Negeri Semarang, 128-135.

Tollazzi, T., \& Rencelj, M. (2012). Typical Deficiencies in Traffic Safety and Irregularities of Slovenian Roads. SIIV - 5th International Congress - Sustainability of Road Infrastructures (hal. 655-663). Rome: Elsevier.

Vardaki, S., Bekiaris, E., \& Kanellaidis, G. (2018). Addressing education and training needs of road. Conget engineering, 1525814. 
Wegman, F. (2017). The Future of Road Safety: A Worldwide Perspective. International Association of Traffic and Safety Sciences Research, 66-71.

Weller, G., Svhlag, B., Gatti, G., Jorna, R., \& Leur, M. V. (2006). Human Factors in Road Design - State of The Art and Empirical Evidence. Road Infrastructure Safety Protection Core Research and Development for Road Safety in Europe; Increasing Safety and Reliability of Secondary Roads for a Sustainable Surface Transport (RIPCORDISEREST). 
